Prepared for the U.S. Department of Energy

under Contract DE-AC05-76RL01830

\title{
Comparison of Routable Control System Security Approaches
}

\author{
TW Edgar \\ DO Manz \\ MD Hadley \\ JD Winn \\ TE Carroll
}

June 2011

Pacific Northwest

NATIONAL LABORATORY

Proudly Operated by Battelle Since 1965 


\title{
DISCLAIMER
}

This report was prepared as an account of work sponsored by an agency of the United States Government. Neither the United States Government nor any agency thereof, nor Battelle Memorial Institute, nor any of their employees, makes any warranty, express or implied, or assumes any legal liability or responsibility for the accuracy, completeness, or usefulness of any information, apparatus, product, or process disclosed, or represents that its use would not infringe privately owned rights. Reference herein to any specific commercial product, process, or service by trade name, trademark, manufacturer, or otherwise does not necessarily constitute or imply its endorsement, recommendation, or favoring by the United States Government or any agency thereof, or Battelle Memorial Institute. The views and opinions of authors expressed herein do not necessarily state or reflect those of the United States Government or any agency thereof.

\author{
PACIFIC NORTHWEST NATIONAI, I.ABORATORY \\ operated by \\ BAT'TELLE \\ for the \\ UNITFD STATES DEPARTMENT OF ENFRGY \\ under Contract DE-ACO5-76RL01830
}

\author{
Printed in the United States of America \\ Available to DOE and DOE contractors from the \\ Office of Scientific and Technical Information, \\ P.O. Box 62, Oak Ridge, TN 37831-0062; \\ ph: (865) 576-8401 \\ fax: (865) 576-5728 \\ email: reports@adonis.osti.gov

\footnotetext{
Available to the public from the National Technical Information Service,

U.S. Department of Commerce, 5285 Port Royal Rd., Springfield, VA 22161

ph: (800) 553-6847

fax: $(703) 605-6900$

email: orders(a) ntis.fedworld.gov

online ordering: http://www.ntis.gov/ordering.htm
}

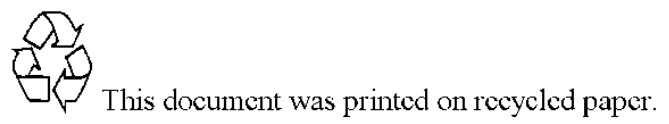

(9/2003) 


\title{
Comparison of Routable Control System Security Approaches
}

\author{
TW Edgar \\ DO Manz \\ MD Hadley \\ JD Winn \\ TE Carroll
}

June 2011

Prepared for the U.S. Department of Energy under Contract DE-AC05-76RL01830

Pacific Northwest National Laboratory

Richland, Washington 99352 


\section{Table of Contents}

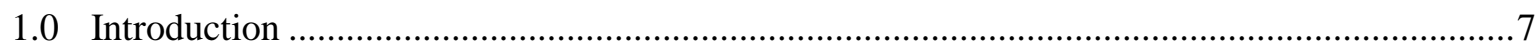

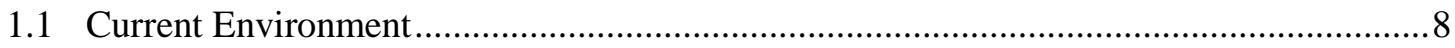

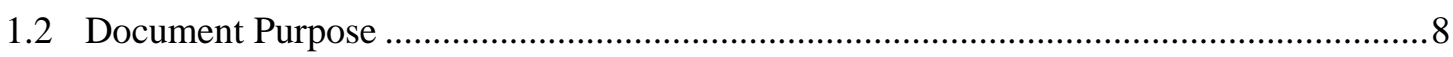

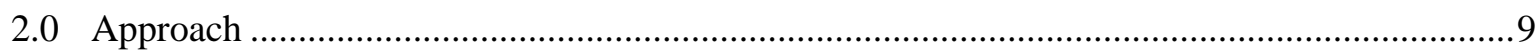

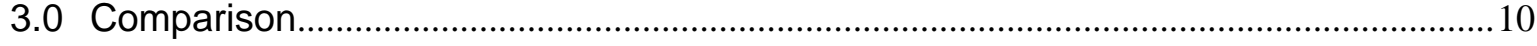

Native Support for Routable Control System Object Protocol ................................................... 10 
Table of Figures

Figure 1: Generic Control System Architecture …............................................................... 


\section{Acronyms and Abbreviations}

\begin{tabular}{|c|c|}
\hline ATM & Asynchronous Transfer Mode \\
\hline COTS & Commercial-off-the-Shelf \\
\hline CROP & Control system Routable Object Protocol \\
\hline CSTP & Control system Secure Transport Protocol \\
\hline DCCP & Datagram Congestion Control Protocol \\
\hline DCS & Distribution Control System \\
\hline DiffServ & Differentiated Services \\
\hline DNP & Distributed Network Protocol \\
\hline DSCP & Differentiated Services Code Point \\
\hline DTLS & Datagram Transport Layer Security \\
\hline FIPS & Federal Information Processing Standard \\
\hline GRE & Generic Route Encapsulation \\
\hline IEC & International Electrotechnical Commission \\
\hline IED & Intelligent Electronic Device \\
\hline $\mathrm{I} / \mathrm{O}$ & Input/Output \\
\hline IP & Internet Protocol \\
\hline IPsec & Internet Protocol Security \\
\hline IT & Information Technology \\
\hline LAN & Local Area Network \\
\hline MBAP & Modbus Application Protocol \\
\hline MPLS & Multi Protocol Label Switching \\
\hline NAT & Network Address Translation \\
\hline NIST & National Institute of Standards and Technology \\
\hline OC & Optical Carrier \\
\hline OPC & OLE (Object Linking and Embedding) for Process Control \\
\hline OSI & Open System Interconnection \\
\hline PMU & Phasor Measurement Unit \\
\hline QoS & Quality of Service \\
\hline RTP & Real-time Transport Protocol \\
\hline RTU & Remote Terminal Unit \\
\hline SCADA & Supervisory Control and Data Acquisition \\
\hline SCTP & Stream Control Transmission Protocol \\
\hline SEM/SIEM & Security Information and Event Manager \\
\hline
\end{tabular}




\begin{tabular}{|l|l|}
\hline SSCP & Secure SCADA Communications Protocol \\
\hline SSH & Secure Shell \\
\hline SSL & Secure Socket Layer \\
\hline SYN & Synchronize flag in TCP \\
\hline TCP & Transmission Control Protocol \\
\hline TLS & Transport Layer Security \\
\hline UDP & User Datagram Protocol \\
\hline VOIP & Voice over Internet Protocol \\
\hline VPN & Virtual Private Network \\
\hline
\end{tabular}




\subsection{Introduction}

The control system environment that monitors and manages the power grid historically has utilized serial communication mechanisms. Leased-line serial communication environments operating at 1200 to 9600 baud rates are common. However, recent trends show that communication media such as fiber, optical carrier 3 (OC-3) speeds, mesh-based highspeed wireless, and the Internet are becoming the media of choice. In addition, a dichotomy has developed between the electrical transmission and distribution environments, with more modern communication infrastructures deployed by transmission utilities.

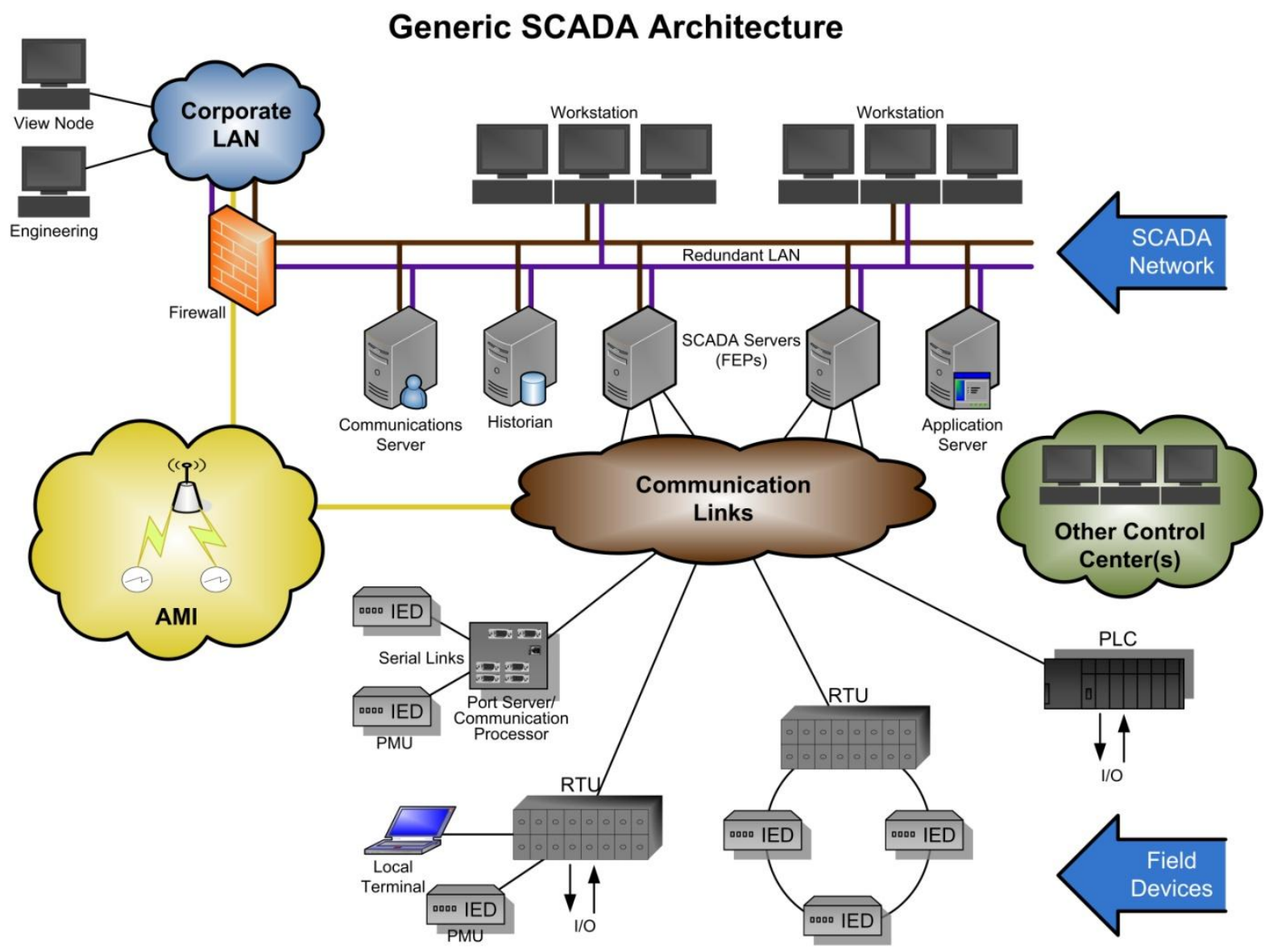

Figure 1: Generic Control System Architecture

The preceding diagram represents a typical control system. The Communication Links cloud supports all of the communication mechanisms a utility might deploy between the control center and devices in the field. Current methodologies used for security implementations are primarily led by single vendors or standards bodies. However, these entities tend to focus on individual protocols. The result is an environment that contains a mixture of security solutions that may only address some communication protocols at an increasing operational burden for the utility. A single approach is needed that meets operational requirements, is simple to operate, and provides the necessary level of security for all control system communication. The solution should be application independent (e.g., Distributed Network Protocol/Internet Protocol [DNP/IP], International Electrotechnical Commission [IEC] C37.118, Object Linking and Embedding for Process Control [OPC], etc.) and focus on the transport layer. In an ideal setting, a well-designed suite of standards for control system communication will be used for vendor implementation and compliance testing. An expected outcome of this effort is an international standard. 


\subsection{Current Environment}

Control system environments are designed to provide centralized control of dispersed physical processes. The data communicated across control systems is used to monitor the state of the physical processes in operation as well as to provide the remote control capability to physically alter the state of the system. The physical processes often have staff and public safety concerns in addition to monetary considerations. Therefore, the data transmitted across the control system has high security requirements for data integrity.

Current control system environments are a mix of legacy serial communication and routable IP communication. Serial communication is slowly being replaced with IP communication as equipment is updated. This document will focus on routable IP communication.

Current routable control system communication over IP is often unsecured. For example, a utility using DNP/IP over utility-owned fiber may not implement Secure DNP or use TLS to increase the level of assurance. Of the protocols that can provide security, the constraints and requirements of control system traffic are ignored in favor of a one-size-fits-all security solution. Consider the use of Internet Protocol Security (IPSec) to establish a virtual private network (VPN) connection over which all communication between a control center and a substation flows. Control and telemetry traffic require very different security policies but are treated the same in VPN tunnels. Internet security solutions are being applied to routable control system traffic without consideration for their requirements. The fundamental limitation of current control system protocols that operate over IP is their assumption that all traffic is equal and should be treated identically. This means that control traffic, data telemetry traffic, physical security data, and engineering maintenance are all secured, tagged, and transported in an identical manner, regardless of how the security objectives for the traffic might differ.

As control system traffic continues to integrate with corporate and public networks, the attack surface increases proportionally. Devices that were disconnected from the Internet are now directly or indirectly accessible worldwide. While this interconnectivity reduces costs and increases productivity, the security risks must be addressed before widespread adoption. The advantage of using commercial-off-the-shelf (COTS) applications, protocols, and devices is that it makes deployment and integration with corporate and public networks much easier. Using popular and well know protocols means that security can often be leveraged from the information technology (IT) world and applied to the control system implementations. However, while this solution unarguably provides security, it will not consider the constraints and requirements of communication traffic in control system networks.

While Internet traffic employs a variety of technologies, the vast majority of all user communication relies upon two popular protocols, Transmission Control Protocol (TCP) and User Datagram Protocol (UDP). Both of these protocols operate on top of the ubiquitous and foundational IP. As online movie and TV watching, Voice over IP (VOIP) communication, online gaming, and other intensive forms of traffic have increased, the limitations of TCP and UDP have become apparent. TCP provides reliable, ordered communication, while UDP provides no quality of service guarantees. They are the two extremes of data transport service. However, these new forms of communication are unsuited for TCP communication and require more assurance than UDP can provide. Numerous new protocols have been or are being developed to suit the streaming, data-intensive nature of the new network traffic. Similarly, control system network traffic should not rely on a one-size-fits-all approach of using the well proven but inflexible TCP or the bare-bones UDP. International Electrotechnical Commission (IEC) IEC-62351 is an example of a control-system specific security effort currently being developed.

\subsection{Purpose}

The purpose of this document is to compare the security requirements identified in PNNL's forward looking protocol design to available technologies and standards. The technologies under consideration were identified using a survey of vendor offerings and IP security technologies. Section 3 describes these technologies in more detail. Please reference the Secure and Efficient Routable Control Systems document for the complete vision, roadmap, functional technology comparison, and derived requirements. 


\subsection{Approach}

The security objectives typically found in IT networks (confidentiality, integrity, and availability) differ in importance for control systems. The nature and purpose of the data in the control system network cause availability and integrity to be critically important. Confidentiality is therefore less important. A multidisciplinary team of researchers at PNNL was used to evaluate the various technologies using the requirements and vision identified in the SSCP Specification for Routable Control System Communication Document and the security objectives of these systems. Popular security solutions, protocols and applications were evaluated in light of the derived requirements in the companion document. See the next section for the results of the comparison. 


\subsection{Comparison}

The following table contains a review of the available security technologies and their ability to natively support the derived requirements of the future control system vision.

\section{Native Support for Routable Control System Object Protocol}

\begin{tabular}{|c|c|c|c|c|}
\hline Derived Requirement & SCTP & UDP/DTLS & $\begin{array}{c}\text { TCP/TLS } \\
\text { (IEC-62351) }\end{array}$ & IP/IPSec \\
\hline Telemetry data must be only authenticated & Yes & Yes & Yes & Yes \\
\hline Telemetry data may optionally be encrypted & Yes & Yes & Yes & Yes \\
\hline Telemetry data must be a best-effort transport & Yes & Yes & No & Yes \\
\hline Telemetry data must be ordered & Yes & No & Yes & No \\
\hline Control data must be reliable transport & Yes & No & Yes & Yes \\
\hline Control data must be authenticated & Yes & Yes & Yes & Yes \\
\hline Control data must be encrypted & Yes & Yes & Yes & Yes \\
\hline Control data must be in-order delivery & Yes & No & Yes & No \\
\hline $\begin{array}{l}\text { Control data must be highest-priority data with best } \\
\text { available quality of service }\end{array}$ & Yes & No & No & No \\
\hline Event data must be authenticated & Yes & Yes & Yes & Yes \\
\hline Event data must be encrypted & Yes & Yes & Yes & Yes \\
\hline Event data must be reliable transport & Yes & No & Yes & No \\
\hline $\begin{array}{l}\text { Transport layer must provide congestion control } \\
\text { mechanism }\end{array}$ & Yes & No & Yes & N/A \\
\hline $\begin{array}{l}\text { Protocol stack must provide dual-homing and multi- } \\
\text { path capabilities }\end{array}$ & Yes & No & No & Yes \\
\hline $\begin{array}{l}\text { Transport layer must provide management of } \\
\text { priority of service }\end{array}$ & Yes & No & No & N/A \\
\hline Transport layer management of distinct streams & Yes & No & No & N/A \\
\hline
\end{tabular}

As is evident, existing protocol do not fully addresses all requirements. Therefore, SCTP was created to satisfy all of the necessary derived requirements. No protocol or solution, in isolation, fully provides the confidentiality, integrity and availability required in control system applications. 